\title{
Cellular immunity in pertussis
}

Considerable advances have been made recently in our understanding of the pathogenesis and the immunological mechanisms involved in the prevention and control of infection by Bordetella pertussis. Traditionally, research on protection has focused on the role of humoral immunity and several reports have shown that passive transfer of antibodies against several putative protective antigens, including pertussis toxin (PT), filamentous haemagglutinin(FHA) and pertactin, can confer a level of protection in mice against intracerebral or respiratory challenge. ${ }^{1}$ However, the results of a clinical trial in Sweden, ${ }^{2}$ as well as a number of active immunisation experiments in mice and rabbits $^{3-5}$ have also failed to find a correlation between serum antibody levels to $B$. pertussis components and protection. While circulating antibodies do play a role, both in toxin neutralisation and in preventing bacterial attachment following transudation into the lungs, evidence is now emerging that cell-mediated immunity may also be required for protection against B. pertussis.

Recent reports have suggested that $B$. pertussis is not exclusively an extracellular pathogen. It has been shown that $B$. pertussis can be taken up and survive within mammalian cells including macrophages in vitro. ${ }^{6,7}$ Furthermore, organisms have been found within alveolar macrophages from the lungs of HIVinfected individuals. ${ }^{7}$ These findings suggest that cellmediated immunity would be required to control an intracellular state of $B$. pertussis, which could escape immune defences mediated by antibody.

The earliest studies on the cellular immune response to $B$. pertussis described the induction and specificity of proliferative $\mathrm{CD}^{+} \mathrm{T}$ cells in human subjects and mice after immunisation or infection..$^{8-13}$ De Magistris and colleagues ${ }^{8,9}$ demonstrated $\mathrm{T}$-cell responses to PT, FHA and pertactin in adults who had suffered from pertussis in childhood. CD4 ${ }^{+} \mathrm{T}$-cell clones specific for FHA and pertactin were established by re-stimulation of peripheral blood mononuclear cells (PBMC) in vitro with killed whole bacteria, whereas PT-specific clones were established only when PT was used for restimulation in vitro. ${ }^{9}$ These findings suggested that PT may not be a major target for $\mathrm{T}$ cells from previously infected individuals or that formaldehyde treatment of the bacteria affected the processing or T-cell recognition of epitopes on PT. Evidence for the latter possibility was provided from observations in our laboratories that $\mathrm{T}$ cells from mice convalescing from $B$. pertussis infection failed to respond to aldehydetreated PT (PTd), but did respond to a sub-mitogenic dose of active PT and to a mutant PT molecule devoid of mitogenicity. ${ }^{12}$ This study showed that FHA, pertactin and agglutinogens 2 and 3 were also recognised by $T$ cells from convalescent mice. ${ }^{12}$

A number of research groups have used synthetic peptides to identify T-cell epitopes on the S-1, S-2, S-3 and S-4 subunits of PT. ${ }^{9,10,13,14}$ Although the definition of $\mathrm{T}$ cells specific for $B$. pertussis antigens provides circumstantial evidence for the role of cellmediated immunity in protection against $B$. pertussis, a direct demonstration of the involvement of $T$ cells has been provided only recently through experiments with the murine respiratory infection model. ${ }^{15}$ It was shown that following aerosol challenge nude mice, which are deficient in $\mathrm{T}$ cells, failed to clear the bacteria and developed a chronic infection. In contrast, normal naive mice cleared the infection within 35 days of challenge. Adoptive transfer of splenic T cells or purified $\mathrm{CD}^{+} \mathrm{T}$ cells, from mice rendered immune by previous infection, into nude or immunosuppressed (sublethally irradiated) recipient mice resulted in elimination of bacteria within 15-20 days of challenge. Furthermore, there were no detectable serum antibodies to $B$. pertussis antigens in the recipients at the time of bacterial clearance. These findings suggest that cell-mediated immunity plays an important role in the elimination of a primary infection and in protection against subsequent challenge.

Our study, ${ }^{15}$ as well as that of Petersen et al. ${ }^{16}$ suggested that spleen cells from convalescent mice produced high levels of IL-2, IFN- $\gamma$ and TNF, but no detectable IL-4 and very low levels of IL-5. This pattern of lymphokine secretion is characteristic of Th1 subpopulations of $\mathrm{CD}^{+} \mathrm{T}$ cells that are predominantly involved in inflammatory, DTH and cytotoxic functions. Furthermore, Peppoloni et al. ${ }^{17}$ showed that $B$. pertussis-specific $\mathrm{CD}^{+}$T-cell clones from previously infected human subjects secrete IL-2 and IFN- $\gamma$, but little or no IL-4, and displayed cytotoxic activity against target cells pulsed with killed bacteria. The studies in mice also showed that proliferative T cell responses to $B$. pertussis antigens could be detected within 2 weeks of infection, whereas anti$B$. pertussis antibodies had not reached significant levels at the time of bacterial elimination. These observations suggest a direct role for Th1 cells in immunity to $B$. pertussis.

In recent investigations, undertaken at NIBSC, we have also found that immunisation of mice with a whole-cell pertussis vaccine induces a good Th1 response and moderate antibody levels. ${ }^{18}$ In contrast, immunisation with an acellular vaccine comprising PTd FHA and pertactin generated a strong antibody 
response and T cells that secreted IL-5, but not IL-2 or IFN- $\gamma$; a lymphokine profile characteristic of $\mathrm{Th} 2$ cells, which are considered to be the true helper $\mathrm{T}$ cells for stimulating antibody response to foreign antigen. The slower bacterial clearance after respiratory challenge of mice immunised with the acellular vaccine, when compared with mice immunised with the wholecell vaccine or convalescent mice, is considered to reflect the failure of the acellular vaccine to induce $B$. pertussis-specific Th1 cells. However, the pattern of bacterial clearance in mice immunised with the acellular vaccine is compatible with the role of antibody, stimulated by Th2 cells, in reducing the numbers of organisms in the lungs early in the course of the infection.

In conclusion, the findings from murine models, as well as circumstantial evidence from studies in man, suggest that, while antibody plays a role in preventing

\section{References}

1. Robinson A, Irons LI, Ashworth LAE. Pertussis vaccine: present status and future prospects. Vaccine 1985; 3: $11-22$.

2. Ad hoc group for the study of pertussis vaccines. Placebocontrolled trial of two acellular pertussis vaccines in Sweden-protective efficacy and adverse events. Lancet $1988 ; 1$ : 955-960.

3. Roberts M, Maskell D, Novotny P, Dougan G. Construction and characterization in vivo of Bordetella pertussis aro $A$ mutants. Infect Immun 1990; 58: 732-739.

4. Shahin RD, Witvliet MH, Manclark CR. Mechanism of pertussis toxin $\mathrm{B}$ oligomer-mediated protection against Bordetella pertussis respiratory infection. Infect Immun $1990 ; 58$ : $4063-4068$.

5. Ashworth LAE, Fitzgeorge RB, Irons LI, Morgan CP, Robinson A. Rabbit nasopharyngeal colonization by Bordetella pertussis: the effects of immunization on clearance and on serum and nasal antibody levels. J Hyg 1982; 88: $475-486$.

6. Ewanowich CA, Melton AR, Weiss AA, Sherburne RK, Peppler MS. Invasion of HeLa 299 cells by virulent Bordetella pertussis. Infect Immun 1989; 57 : 2698-2704.

7. Bromberg K, Tannis G, Steiner P. Detection of Bordetella pertussis associated with the alveolar macrophages of children with human immunodeficiency virus infection. Infect Immun 1991; 59: 4715-4719.

8. De Magistris MT, Romano M, Nuti S, Rappuoli R, Tagliabue A. Dissecting human $\mathrm{T}$ cell responses against Bordetella species. $J$ Exp Med 1988; 168: 1351-1362.

9. De Magistris MT, Romano M, Bartoloni A, Rappuoli R, Tagliabue A. Human T cell clones define $S 1$ subunit as the most immunogenic moeity of pertussis toxin and determine its epitope map. J Exp Med 1989; 169: 1519-1532.

10. Oksenberg JR, Judd AK, Ko C et al. MHC-restricted rec- colonisation and combating toxin-mediated disease, complete bacterial clearance requires cellular immune responses mediated by Th1 cells. Th1 cells could operate to stimulate the recruitment, phagocytic function and intracellular killing of $B$. pertussis by macrophages. Th1 cells could also function through their cytotoxic activity against the infected macrophages and thereby allow subsequent destruction of the intracellular reservoirs of the bacteria. Whatever the mechanism, it is now established that $T$ cells are induced by immunisation and infection, and that these $T$ cells play a vital role, not only in regulation of the antibody response, but in direct cell-mediated immunity against $B$. pertussis.

K. H. G. Mills* and K. RedheAD *Department of Biology, St Patrick's College, Maynooth, Ireland. Division of Bacteriology, National Institute for Biological Standards and Control, Blanche Lane, South Mimms, Hertfordshire EN6 30G. ognition of immunogenic $\mathrm{T}$ cell epitopes of pertussis toxin reveals determinants in man distinct from the ADPribosylase active site. $J$ Exp Med 1988; 168: 1855-1864.

11. Gearing AJH, Bird CR, Redhead K, Thomas M. Human cellular immune responses to Bordetella pertussis infection. FEMS Microbiol Immunol 1989; 1: 205-211.

12. Mills KHG, Barnard A, Watkins J, Redhead K. Specificity of the $\mathrm{T}$ cell response to Bordetella pertussis in aerosolinfected mice. In: Manclark CR (ed) Proceedings of the Sixth International Symposium on Pertussis. Bethesda, MD, US Public Health Service. 1990: 166-174.

13. Chong $P$, Zobrist $G$, Sia $C$, Loosmore S, Klein M. Identification of T- and B-cell epitopes of the S2 and S3 subunits of pertussis toxin by use of synthetic peptides. Infect Immun $1992 ; 60: 4640-4647$.

14. Petersen JW, Holm A, Ibsen PH, Hasløv K, Capiau C, Heron I. Identification of human T-cell epitopes on the $\$ 4$ subunit of pertussis toxin. Infect Immun 1992; 60: 3962-3970.

15. Mills KHG, Barnard A, Watkins J, Redhead K. Cell-mediated immunity to Bordetella pertussis: Role of Th1 cells in bacterial clearance in a murine respiratory infection model. Infect Immun 1993; 61 : 399-410.

16. Petersen JW, Ibsen PH, Hasløv K, Heron I. Proliferative responses and gamma interferon and tumor necrosis factor production by lymphocytes isolated from tracheobroncheal lymph nodes and spleens of mice aerosol infected with Bordetella pertussis. Infect Immun 1992; 60: 4563-4570.

17. Peppoloni S, Nencioni L, Di Tommaso A et al. Lymphokine secretion and cytotoxic activity of human $\mathrm{CD}^{+} \mathrm{T}$-cell clones against Bordetella pertussis. Infect Immun 1991; 59: 3768-3773.

18. Redhead K, Watkins J, Barnard A, Mills KHG. Effective immunization against Bordetella pertussis respiratory infection in mice is dependent on induction of cell-mediated immunity. Infect Immun 1993; in press. 